\title{
Physicomechanical Properties of Nano Polystyrene Nanocomposites
}

\author{
A.M. Motawie ${ }^{1}$, S.M. Ahmed ${ }^{1}$, E.A. EL-Sabbagh ${ }^{2}$, N.A. \\ Mansour ${ }^{1}$, D.E. Abulyazied, ${ }^{1}$ E.S. Ali ${ }^{1 *}$ \\ ${ }^{1}$ Petrochemical Department, Egyptian Petroleum Research \\ Institute EPRI, Nasr City, ${ }^{2}$ Physical Department, Faculty of \\ Science, Al-Azhar University, Cairo, Egypt.
}

\begin{abstract}
D REPARATION of nano metal oxides $\left(\mathrm{Fe}_{2} \mathrm{O}_{3}, \mathrm{ZnO}\right.$ and $\left.\mathrm{TiO}_{2}\right)$ and nano sphere polystyrene (PS) has been done in micellar solution. Nanocomposite films have been prepared by doping nano polystyrene with different ratios of nano metal oxide ranged from 0.25 up to 3 wt $\%$. These nanocomposites were characterized using transmission electron microscopy (TEM), X-ray diffraction (XRD) and Fourier transform infrared spectroscopy (FTIR).Thermo gravimetric analysis (T GA) and mechanical properties have also been investigated. By comparison with the values obtained for the PS, it was observed that the thermal stability is higher for the nanocompoistes and increases with increasing the nano metal oxides concentration in these samples. The results indicate that the tensilestrength, elongation at break and Young's modulus of all the nanocomposites enhanced with the addition of metal oxides nanoparticles compared with the pure PS.
\end{abstract}

Keywords: Polystyrene, Nanocompoistes, Nano metal oxides, Thermal stability, Mechanical properties.

Composite structures comprising metal nanoparticles (NPs) and polymer submicro spheres have attracted much attention due to their applications in such areas as catalysis, optics, biological sensing [1-6].The usage of nano-crystals (NCs) as polymer fillers relates to the strong current interest in development and application of new materials [7,8]. These, so-called, polymer nanocomposites take advantage of large specific surface area and size-dependent properties of NCs as well as desired properties of host polymers such as possibility to be designed in various shapes, long-term stability and reprocess ability [9]. The inorganic nanoparticles have been used to create nanocomposites since the early 1990s, and improvements the properties of polymer matrix in strength, modulus, and fracture strength have been seen for a variety of nanocomposite systems. The nanoparticles used provide improved interfacial surface area and smaller inter particle distances, which are improved the mechanical properties [10-12]. The polystyrene (PS) is a hydrophobic polymer frequently used as a matrix for a

*Corresponding author e-mail: emansaad_80@yahoo.com,

Telephone No.: 00202 22747917, Fax No.: 0020222747433

DOI: $10.21608 /$ ejchem. 2017.2928

(C2017 The National Centerfor in Formation\& Documentation (NIDOC) 
variety of fillers such as organoclays [13,14], metals [15,16], oxides [17,19], metal chalogenides [20-22]and graphite [23] Due to their high surface to bulk ratio, nanoparticles can significantly change thermal as well as mechanical properties of the polymer matrix even when the content of the inorganic phase is quite low [9]. The influence of ferric oxide nanoparticles on the mechanical and thermal properties of polymer nanocomposites has been widely studied [9,17,18,24-29]. In addition, $\mathrm{ZnO}$ nanoparticles have been demonstrated to improve mechanical, optical, thermal properties and crystallization extent in polymers[30]. The $\mathrm{ZnO}$ /polymer nanocomposite materials, due to the good dispersion of $\mathrm{ZnO}$ nanoparticles in the polymer, is interesting in applying in coatings, plastics, sealants and fibers [31]. $\mathrm{TiO}_{2}$ is an ideal inorganic reinforcing component in manufacturing nanocomposites materials with promising properties and applications[32]. The influences of $\mathrm{TiO}_{2}$ nanoparticles on the properties of some $\mathrm{TiO}_{2}$ /polymer nanocomposites, such as antibacterial activity, the mechanical properties, UV absorber and photo catalysis degradation were reported [33-39]. The combination of sodium dodecyl sulfate (SDS) surfactant and a polymer and their synergetic effects to stabilize the colloidal systems have been studied [40-42]. (SDS) also, has been used as a good dispersing agent for halloysite (HNT) in polystyrene/halloysite nanocomposites [43].

In this work, sodium dodecyl sulfate (SDS) have been used as capping agent for preparing nano metal oxides $\left(\mathrm{Fe}_{2} \mathrm{O}_{3}, \mathrm{ZnO}\right.$ and $\left.\mathrm{TiO}_{2}\right)$ and nano sphere polystyrene (PS). Also, the nanocomposites were prepared by solution casting method. The prepared nanocomposites were characterized. The influence of nano-metal oxides on the mechanical and thermal properties of the metal oxides/PS nanocomposites was discussed.

\section{Materials and chemicals}

\section{Experimental}

Sodium dodecyl sulfate (analytic reagent (AR), 99.5\%), potassium persulfate (AR, 99.5\%), styrene (chemically pure (CP), 99.0\%) were purchased from Sinopharm Chemical Reagent Co., Ltd. Fe( $\left(\mathrm{NO}_{3}\right)_{3}, \mathrm{Zn}\left(\mathrm{NO}_{3}\right)_{2}, \mathrm{TiCl}_{4}$, acetone and xylene. The chemicals were used as received, except removal of inhibitor from the styrene with $10 \mathrm{wt} \%$ sodium hydroxide solution in a separating funnel twice to remove the anti polymerizer. Deionized water with a resistivity exceeding 18.0 MV cm from a JL-RO 100 Millipore-Q Plus water purifier was used throughout.

\section{Preparation of nanosphere Polystyrene}

PS nanosphere was prepared using emulsion polymerization [1]. Sodium dodecyl sulfate (SDS) $0.15 \mathrm{~g}$ and potassium persulfate $0.1 \mathrm{~g}$ were dis solved in 70 $\mathrm{ml}$ aqueous ethanol in a $250 \mathrm{ml}$ two-neck flask, and then $4.5 \mathrm{ml}$ of styrene was added to the flask under nitrogen atmosphere. The resulting mixtu re was rapidly

Egypt. J. Chem. 60, No. 2 (2017) 
stirred for $8 \mathrm{~h}$ at $70^{\circ} \mathrm{C}$ to ensure polymerization. The suspension was removed from nitrogen atmosphere, and the product obtained by de-emulsification, the product was washed, and dried. The yield of prepared PS was about $70-75 \%$ with Mwt about 65,000.

Preparation of nano metal oxides

In the typical procedure, $100 \mathrm{~mL}$ of $0.05 \mathrm{M}$ solution of surfactant (sodium dodecyl sulfate (SDS) was made in distilled water and divided into two parts. These two parts were used to prepare $0.5 \mathrm{M}$ metal precursors $\left[\mathrm{Fe}\left(\mathrm{NO}_{3}\right)_{3}\right.$, $\mathrm{Zn}\left(\mathrm{NO}_{3}\right)_{2}$ and $\left.\mathrm{TiCl}_{4}\right]$ and $2 \mathrm{M} \mathrm{NaOH}$ separately. The solution of $\mathrm{NaOH}$ was added using a dropping funnel under stirring. The stirring was continued for $2 \mathrm{~h}$ after the completion of addition of $\mathrm{NaOH}$. The solution was left to age for $12 \mathrm{hrs}$. The solution was centrifuged to obtain the precipitate. The precipitate was washed with water and acetone to remove the unreacted materials and organic impurities. The precursor was dried in an electric oven at $110^{\circ} \mathrm{C}$. The dried product was then crushed and calcined at $200^{\circ} \mathrm{C}$ for $3 \mathrm{hrs}$ [44].

\section{Preparation of metal oxides /PS nanocomposites}

The preparation of metal oxides $\left(\mathrm{Fe}_{2} \mathrm{O}_{3}, \mathrm{ZnO}\right.$ or $\left.\mathrm{TiO}_{2}\right) / \mathrm{PS}$ nanocomposites is based on the dispersion of nanometal oxides in to the organic solvent by ultrasonic radiation for $10 \mathrm{~min}$. The nano metal oxides colloid was then combined in appropriate ratio with PS dissolved in xylene, the solution also dispersed ultrasonically for $20 \mathrm{~min}$. and finally after evaporation of the solvent, a transparent metal oxides /PS nanocomposite film was obtained.

\section{Characterization and measurements}

Transmission electron microscopy (TEM) micrographs were taken using a JEOL JX 1230 TEM with micro-analyzer electron probe. X-ray diffraction (XRD) measurements were performed on a Philip's X-ray diffractometer PW 1390 with Ni-filtered $\mathrm{Cu} \mathrm{K \alpha}$ radiation at generator voltage of $40 \mathrm{kV}$ and wavelength of $0.154 \mathrm{~nm}$ at room temperature. The diffraction angle, 20, was scanned at a rate of $2^{\circ} \mathrm{min}^{-1}$. FTIR spectra of samples were obtained using a Jascow FTIR 430 series infrared spectrophotometer equipped with $\mathrm{KBr}$ discs. Thermogravimetric analysis TGA was carried out using a detector type Shimadzu TGA-50H at a heating rate of $10 \mathrm{deg} \mathrm{min}^{-1}$ from 50 to $600^{\circ} \mathrm{C}$ under nitrogen atmosphere and the sample weight was about $8-10 \mathrm{mg}$. The physicomechanical properties (viz., the tensile strength, elongation at break and Young's modulus) of the prepared nanocomposites were determined according to standard methods using an electronic Zwick tensile testing machine, model 1425. 


\section{Results and Discussion}

\section{Characterization of the nanocomposites}

\section{Particle texture}

The morphology of Nano PS, $\mathrm{Fe}_{2} \mathrm{O}_{3}, \mathrm{ZnO}$ and $\mathrm{TiO}_{2}$ nanoparticles (Fig.1.a-d) and Nano metal oxide/PS composites was examined by TEM (Fig. 2a-c). (Fig. 1a) shows the TEM image of prepared PS spheres in (SDS). The individual particles have smooth and bare surfaces. The PS spheres show good monodispersity with diameters of $60-80 \mathrm{~nm}$. While, the images of the prepared metal oxide samples indicated that the nanoparticles were highly crystalline, and could be well indexed to the hexagonal structure of pure metal oxides $\left(\mathrm{ZnO}\right.$ and $\left.\mathrm{TiO}_{2}\right)$ and appearance of some small like rod $\left(\mathrm{Fe}_{2} \mathrm{O}_{3}\right)$ uniform single particles. Solans et al. [45] had reported that in the binary system (water/surfactant), selfassembled structures of different types can be formed, ranging, for example, from spherical and cylindrical micelles to lamellar phases, which may coexist with predominantly aqueous phases. So, the micelles route can be employed for obtaining the shape and size controlled of the metal oxide NPs. The metal precursors will interact with the (SDS) surfactant molecules in the solution and some chemical reactions and capping effects will happen. The metal precursors are hydrolysis to their initial product (metal hydroxide) and finally form metal oxide nanoparticles after calcination. When SDS solution is bigger than its critical micelle concentration (CMC), the capping effect of surfactant becomes dominant as the SDS molecules will form a protection bilayer or surface micelles on the particle surface. As shown in Fig. 1b, the $\mathrm{Fe}_{2} \mathrm{O}_{3}$ nanoparticles aggregate and elongated into big rod-like particles, with average particle sizes of (20$85 \mathrm{~nm}$ ), while the obtained $\mathrm{ZnO}$ and $\mathrm{TiO}_{2}$ nanoparticles are hexagonal, with average particle sizes of (11-28nm), (12-30 nm), respectively (Fig.1c\& d ).

Moreover, the TEM image of metal oxide/PS nanocomposites (Fig.2), the dark background represented polymer matrix and black dots displayed nanometal oxide nanoparticles distributed in the PS as the filler. Evidently, different capability for charge transport of the filler and the polymer matrix has resulted in the contrast between the nanoparticles and the polymer matrix.

The EDX analysis is shown in Fig.3.which shows the presence of Fe, $\mathrm{Zn}$ and Ti beside the presence of $\mathrm{O}_{2}$ these results are been confirmed by XRD.

\section{XRD diffraction}

X-ray diffraction spectra of pure nano PS and metal oxides/PS nanocomposites are shown in Fig.4.

Egypt. J. Chem. 60, No. 2 (2017) 
The XRD pattern of pure PS is specified by a broad diffraction peak at $2 \theta$ $=20^{\circ}$ indicated that the PS nanoparticles were amorphous materials.
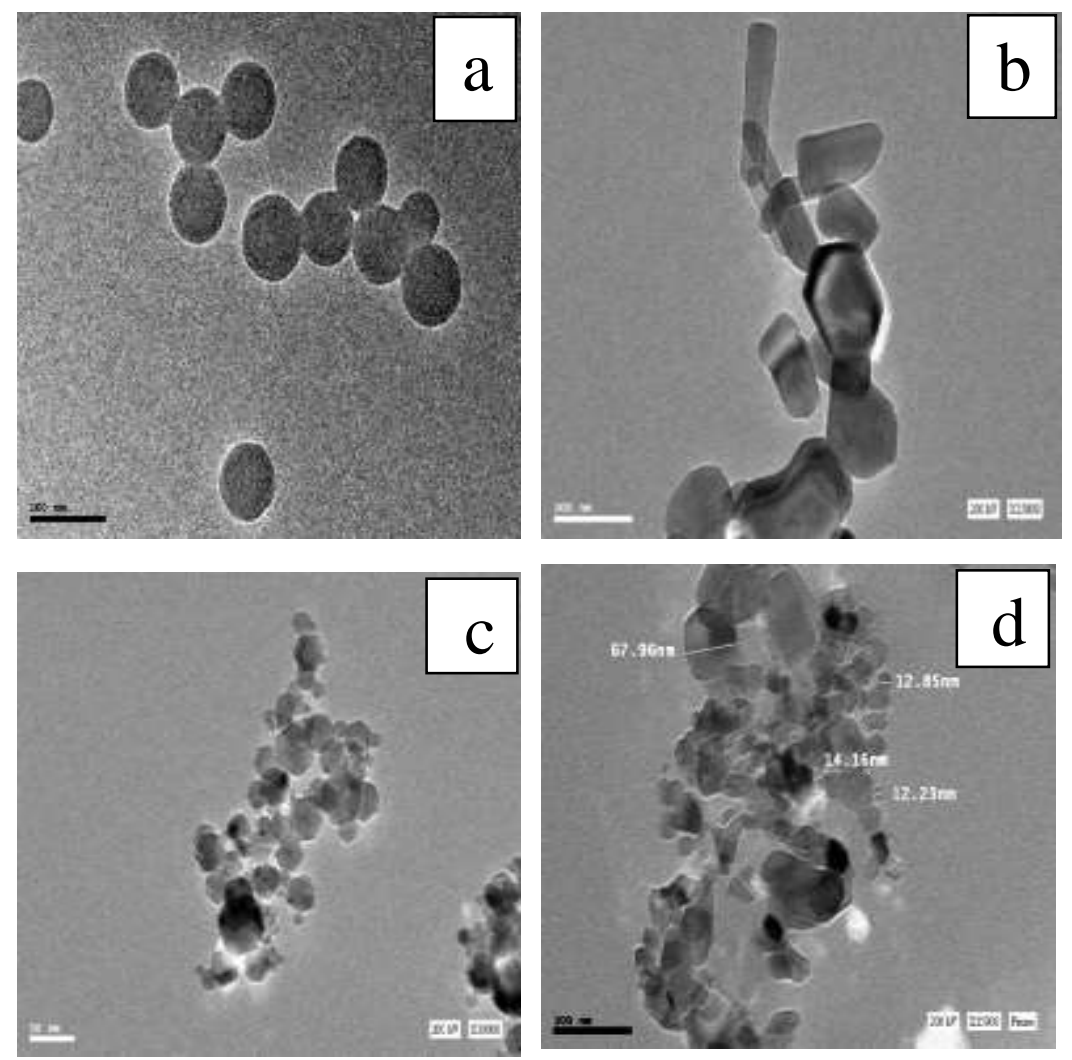

Fig.1a. TEM images of as-prepared PS spheres (b-d) $\mathrm{Fe}_{2} \mathrm{O}_{3}, \mathrm{ZnO}$ and Ti nanometal oxides.
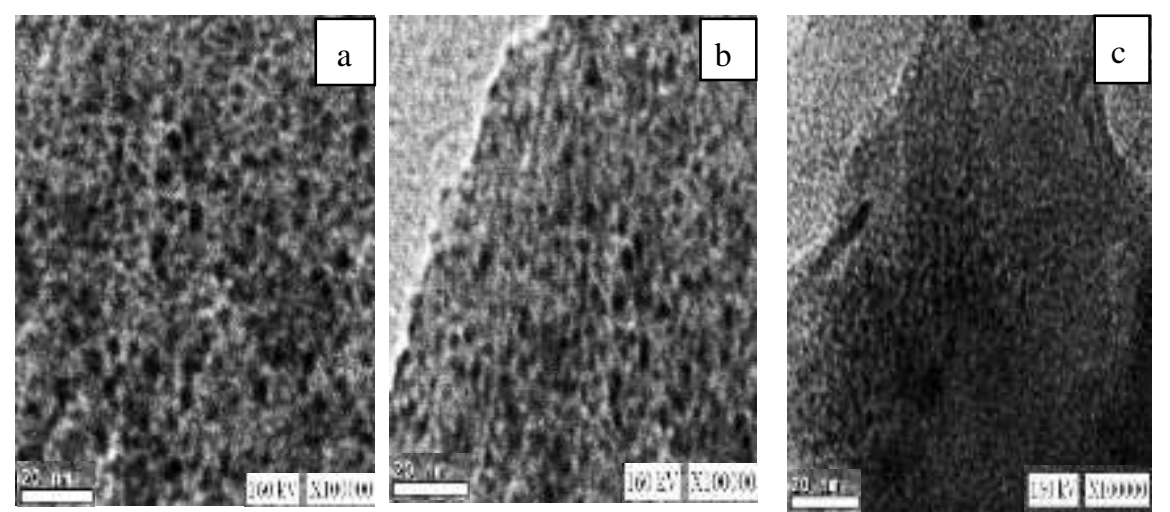

Fig.2. TEM of nanocomposites (a) $\mathrm{Fe}_{2} \mathrm{O}_{3} / \mathrm{PS}$, (b) $\mathrm{ZnO} / \mathrm{PS}$ and (c) $\mathrm{TiO}_{2} / \mathrm{PS}$.

Egypt. J. Chem. 60, No. 2 (2017) 

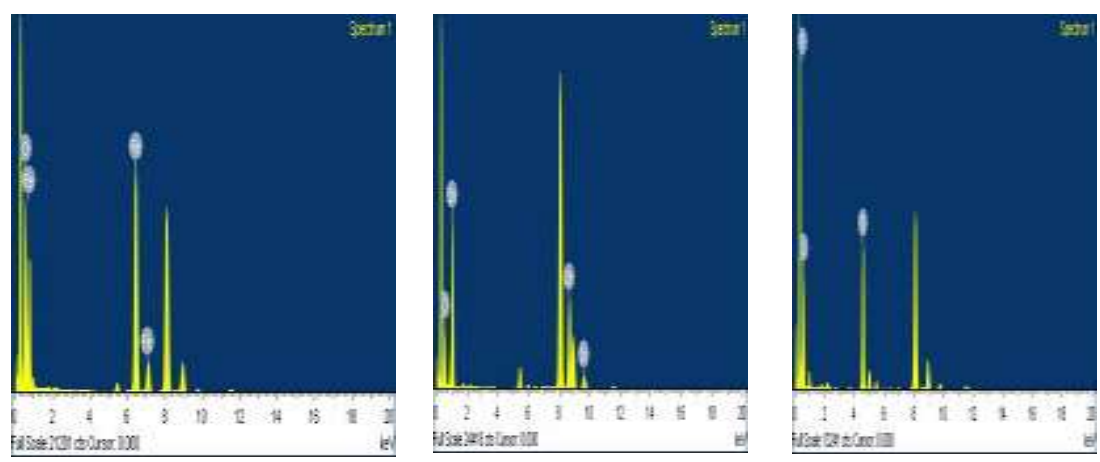

Fig.3. EDX pattern of $\mathrm{PS} / \mathrm{Fe}_{2} \mathrm{O}_{3}, \mathrm{ZnO} / \mathrm{PS}$, andTiO $2 / \mathrm{PS}$ nanocomposites

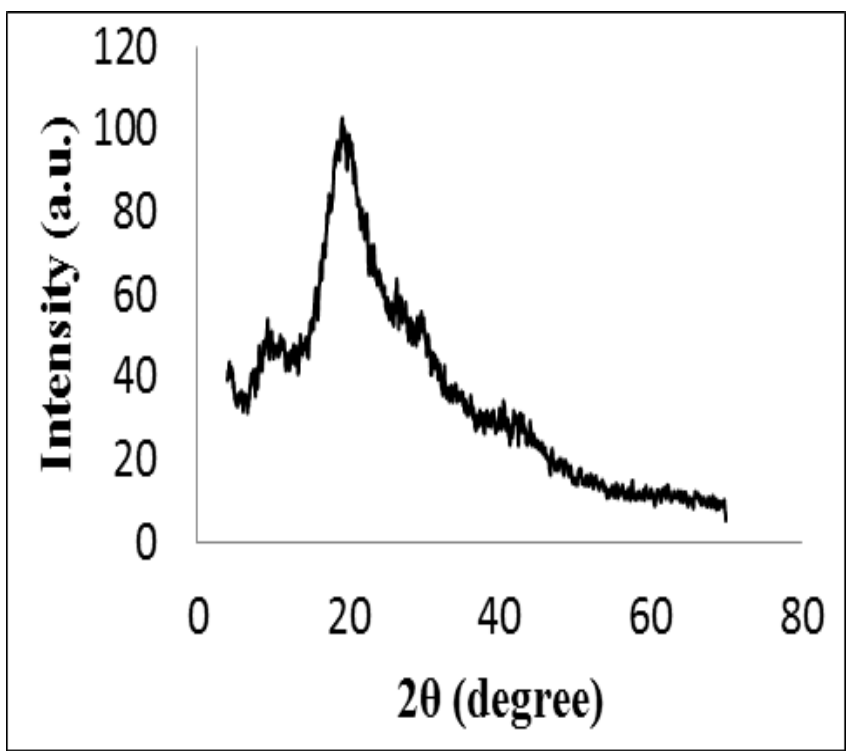

Fig.4. XRD pattern of PS sphere nanoparticles.

The X-ray diffraction spectra of $\mathrm{Fe}_{2} \mathrm{O}_{3} / \mathrm{PS}$ nanocomposites is shown in Fig.5 a. Existence of characteristic peaks of iron oxide indicates presence of this inorganic material in hybrid PS nanocomposite. The locations of expected Bragg reflections and peaks at the $2 \theta$ angles of $30.18^{\circ}(\mathrm{d}=2.962 \AA) ; 35.68^{\circ}(\mathrm{d}=2.522$ $\AA) ; 43.48^{\circ}(\mathrm{d}=2.083 \AA) ; 53.98^{\circ}(\mathrm{d}=1.606 \AA) ; 59.88^{\circ}(\mathrm{d}=1.546 \AA)$; and $62.48^{\circ}$ (d=1.487 $\AA$ ) corresponding to $\alpha-\mathrm{Fe}_{2} \mathrm{O}_{3}$ crystalline structure [9].

Meanwhile, Fig. 5 b shows sharp diffraction peaks of $\mathrm{ZnO}$ can be observed at scattering angles $(2 \theta)$ value of $31.83^{\circ}, 34.49^{\circ}, 36.26^{\circ}, 47.59^{\circ}, 56.56^{\circ}, 62.86^{\circ}$, Egypt. J. Chem. 60, No. 2 (2017) 
$68.12^{\circ}$, and $69.14^{\circ}$ correspond to d spacing $2.81 \AA, 2.60 \AA$, $2.47 \AA, 1.91 \AA, 1.62 \AA$, $1.47 \AA, 1.37 \AA$ and $1.35 \AA$, respectively [46]. In the case of $\mathrm{TiO}_{2} / \mathrm{PS}$ nanocomposite appearance of the peaks at $2 \theta=25.4^{\circ}, 37.9^{\circ}, 48.0^{\circ}, 53.9^{\circ}$ and $55.2^{\circ}$, corresponding to the anatase crystalline form of $\mathrm{TiO}_{2}$ as shown in Fig.5 c [32,39]. As well as, it is observed that the peak intensities of the metal oxide phases increased with increasing metal oxides contents.

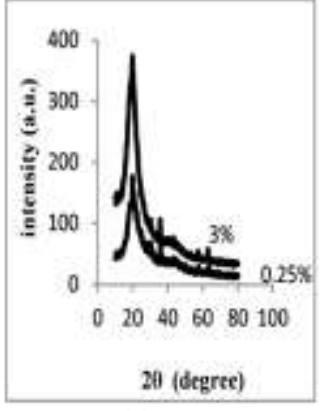

(a)

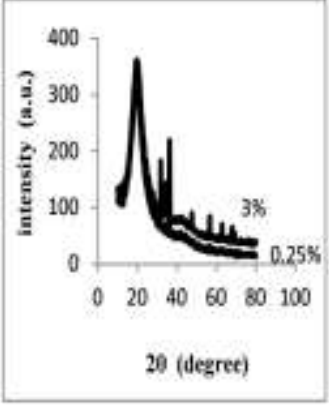

(b)

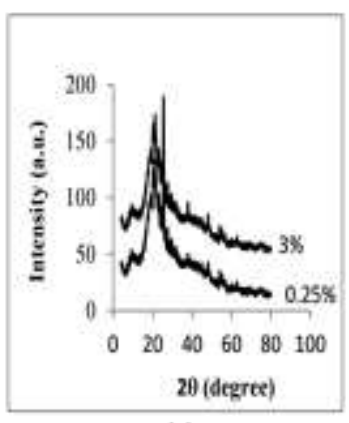

(c)

Fig.5. XRD pattern of (a) $\mathrm{PS} / \mathrm{Fe}_{2} \mathrm{O}_{3}$ (b) PS/ZnO(c) $\mathrm{PS} / \mathrm{TiO}_{2}$ nano-composite particles at two different wt \%

\section{FTIR analysis}

The FTIR spectra of the pure PS nanoparticles and $\mathrm{Fe}_{2} \mathrm{O}_{3}$ and $\mathrm{ZnO} / \mathrm{PS}$ Nanocomposite are shown in Fig.6, the prominent PS absorption peaks at 3024, 2920, 1720, 1460, and $1056 \mathrm{~cm}-1$ indicating aliphatic $\mathrm{C}-\mathrm{H}$ stretching, aromatic $\mathrm{C}-\mathrm{H}$ stretching, aliphatic $\mathrm{CH}_{2}$ and different conformation sensitive vibrational modes of PS, respectively. There was no significant change in the peak positions apart from the peak intensity, indicating that the PS nanoparticles in pure and nanocomposite form show the same structural features [47].

\section{The properties of the nanocomposites}

Thermal Gravimetric Analysis TGA

The thermal stability of polymeric blend is usually studied by thermogravimetric analysis (TGA). The weight loss due to the formation of volatile products after degradation at high temperature is monitored as a function of temperature. When heating occurs under an inert gas flow, a non-oxidative degradation occurs, while the use of air or oxygen allows oxidative degradation of the samples. Generally, the incorporation of nano metals into the polymer matrix was found to enhance thermal stability [48]. 


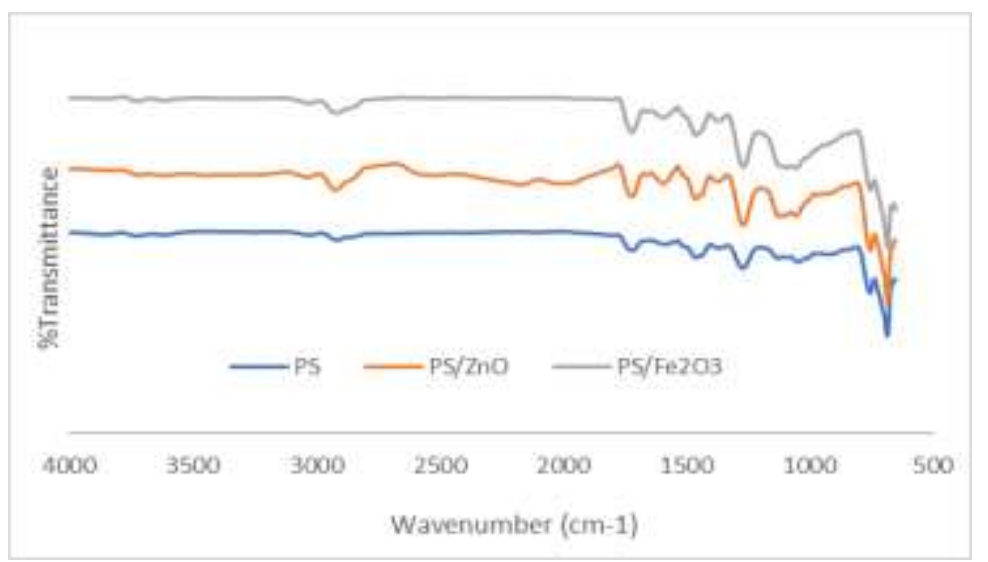

Fig.6. FTIR spectra of the pure PS nanoparticles and $\mathrm{PS} / \mathrm{Fe}_{2} \mathrm{O}_{3}$ and $\mathrm{PS} / \mathrm{ZnO}$ nanocomposites

TGA thermograms of the PS and PS/metal oxides nanocomposites are shown in Fig.7. It is clearly seen from the curves that the starting decomposition temperatures of the nanocomposites were nearly equivalent to that of pure PS sphere. The decomposition temperatures of all samples at $10 \%, 50 \%$ loss of the weight and maximum temperature were showed in Table 1.

We could see from Table 1, the decomposition temperatures of $\mathrm{Fe}_{2} \mathrm{O}_{3} / \mathrm{PS}$, $\mathrm{ZnO} / \mathrm{PS}$ and $\mathrm{TiO}_{2} / \mathrm{PS}$ at $10 \mathrm{wt} . \%$ loss increased by 6,2 and $4^{\circ} \mathrm{C}$ respectively compared with unreinforced PS sphere. As well as, the maximum decomposition temperatures increased by 2,5 and $10{ }^{\circ} \mathrm{C}$ respectively, this indicated that the thermal stability of the nanocomposites was enhanced. The reason may be due to formation of chemical bonds between nano-filler and polymer chains [2].The char residue is found to be higher for the nanocomposites than that of the neat PS, which confirms that the thermal stability of the PS nanocomposites was enhanced due to the presence of the nano-particles.

TABLE 1. Thermal Parameters of the polymer nanocomposites.

\begin{tabular}{|l|c|c|c|c|}
\hline Sample & $\mathrm{T}_{10 \%}{ }^{\mathrm{C}}$ & $\mathrm{T}_{50 \%}{ }^{\circ} \mathrm{C}$ & $\mathrm{T}_{\text {max }}{ }^{\circ} \mathrm{C}$ & $\begin{array}{c}\text { Char Residue } \\
\text { Wt \% at } \\
600{ }^{\circ} \mathrm{C}\end{array}$ \\
\hline $\mathrm{PS}$ & 246 & 384 & 405 & 0.87 \\
\hline $\mathrm{PS} / \mathrm{Fe}_{2} \mathrm{O}_{3}$ & 252 & 384 & 407 & 3.31 \\
\hline $\mathrm{PS} / \mathrm{ZnO}$ & 248 & 375 & 410 & 5.81 \\
\hline $\mathrm{PS} / \mathrm{TiO}{ }_{2}$ & 250 & 401 & 415 & 6.41 \\
\hline
\end{tabular}

Mechanical properties

It is well known that the addition of nanosized materials into the polymer alters its mechanical properties [32]. The influence of nanoparticles $\left(\mathrm{Fe}_{2} \mathrm{O}_{3}, \mathrm{ZnO}\right.$

Egypt. J. Chem. 60, No. 2 (2017) 
and $\mathrm{TiO}_{2}$ ) on the mechanical properties of PS was investigated by tensile strength, the elongation at break $(\mathrm{Eb})$ and Young's modules of the film. The corresponding values of the tensile strength, elongation at break and the modulus of the nanocomposites were determined and plotted against the content of the nanoparticles weight \%. These plots are shown in Fig. 8, 9 and 10 respectively.

For the tensile strength, some observations can be seen from Fig. 8. First, there is an increase in the tensile strength for the nanocomposites samples than that of the Pure PS. Second, there is an enhancement of the tensile strength for $\mathrm{TiO}_{2}$ and $\mathrm{Fe}_{2} \mathrm{O}_{3}$ nanocomposites till 0.75 wt. $\%$ nanoparticles content, where the tensile improved by $46 \%$ and $100 \%$ for them respectively at $0.75 \mathrm{wt} \%$. Then the tensile strength decrease with increasing the content in the range of 1-3 wt $\%$. Third, the tensile strength increases till 2 wt. $\%$ for nano- $\mathrm{ZnO}$ and improved by $204 \%$ at $2 \%$, then the tensile decline only at $3 \mathrm{wt} . \%$. It is logically expected that the agglomeration of nanoparticles at relatively high nanoparticles contents in polymer matrix should be responsible for the above tensile loss. Fourth, $\mathrm{ZnO} / \mathrm{PS}$ nanocomposites give the higher values of the tensile and the $\mathrm{Fe}_{2} \mathrm{O}_{3}$ nanocomposites give the least.

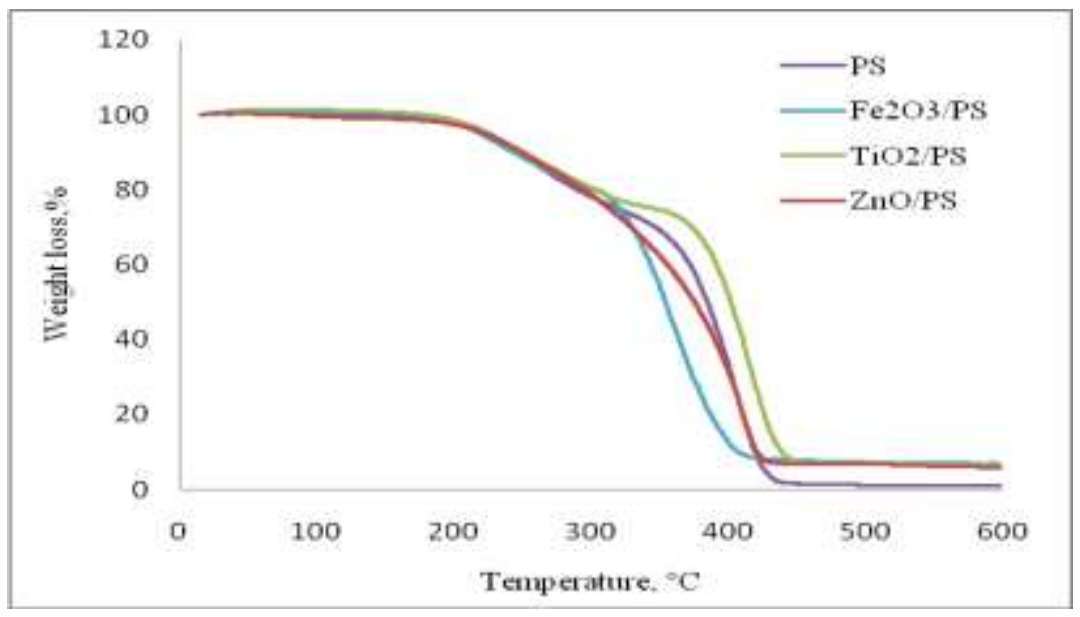

Fig.7. TGA curves of PS and PS/ nanocomposites particles 


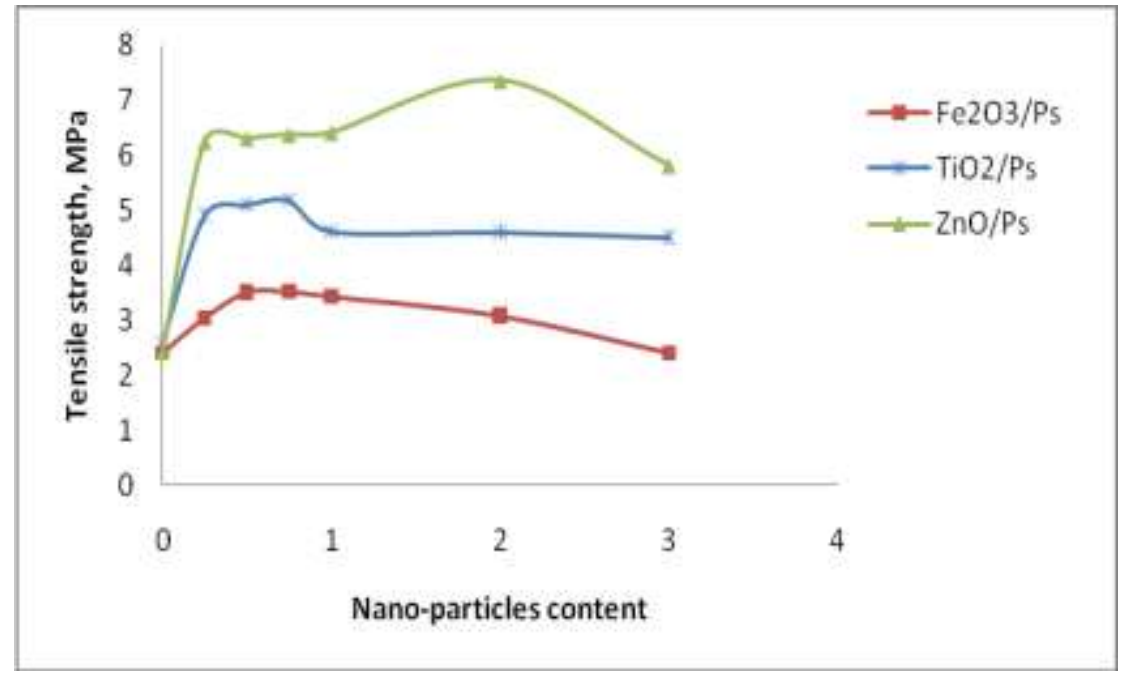

Fig.8. The effect of nano-particles content on the tensile strength of of PS/ nanocomposite

The increase in the strength of the composites up to $0.75 \%$ nano- $-\mathrm{Fe}_{2} \mathrm{O}_{3}, \mathrm{TiO}_{2}$, and up to $2 \%$ nano- $\mathrm{ZnO}$ may be due to the well-dispersed nanoparticles and the improved interfacial adhesion up to theses concentrations. The homogenous dispersion of nanoparticles in high concentrations is difficult. Likely, nano-sized particles have high surface energy and thus, they are easy to aggregate. which results in decreasing the strength of the composites, at high concentrations of nano-particles [49].

The effect of nano-particles addition on the values of elongation at break of nanocomposites is shown in Fig. 9. It is shown from the figure that the elongation enhanced with the addition of the nano- $\left(\mathrm{Fe}_{2} \mathrm{O}_{3}\right.$ and $\left.\mathrm{TiO}_{2}\right)$ up to $0.75 \%$, then decay up to $3 \%$ which are in good agreement with tensile strength experiment. However, for $\mathrm{ZnO}$ nanocomposites the elongation decreases than the pure PS. This reduction is attributed to stiffening of the matrix by the nanoparticles which due to restrictions on the mobility of polymer chains during stretching by the tethering nano particles [50]. Chae, D.W et al. [51] found that the introduction of $\mathrm{ZnO}$ nanoparticles into polystyrene (PS) decreased both the tensile strength and elongation to break. This implies that the interfacial adhesion is not strong enough to stand up to large mechanical forces. The effect of nanoparticles addition on tensile modulus is seen in Fig. 10. Tensile modulus of pure PS is $0.007 \mathrm{MPa}$. It is observed that the modulus of nanocomposites increases tangentially with increasing nano- $\mathrm{Fe}_{2} \mathrm{O}_{3}$ content up to $0.75 \%$., where the modulus is enhanced by $15 \%$ only at $0.75 \%$ content. However on addition of nano-TiO2 and nano- $\mathrm{ZnO}$, the modulus increases dramatically up to $2 \%$ content. The highest improvement of the modulus for nano- $\mathrm{TiO}_{2}$ and nano- $\mathrm{ZnO}$

Egypt. J. Chem. 60, No. 2 (2017) 
respectively was 97.6 and $355 \%$ at $0.75 \mathrm{wt} \%$. The reason for the increase in mechanical properties is due to the fact that the small diameter of the particles themselves will contribute a very high-interfacial surface area and increase the mechanical properties of the polymer.

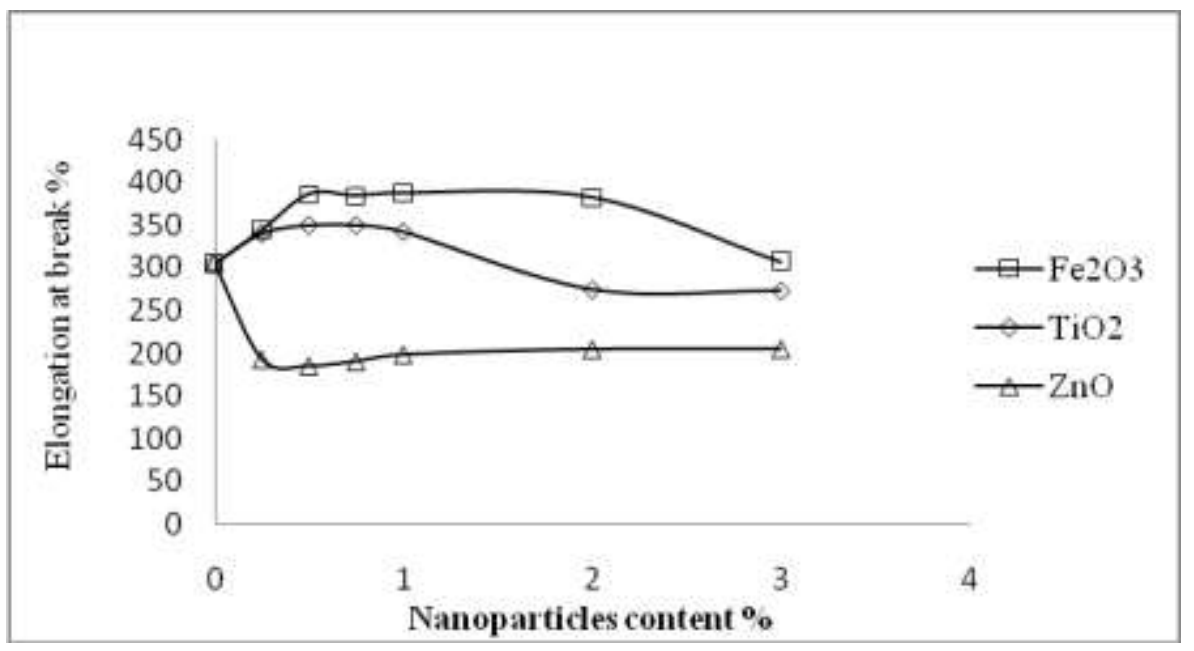

Fig.9. Effect of nano-particles content on the elongation at break of PS/ nanocomposite

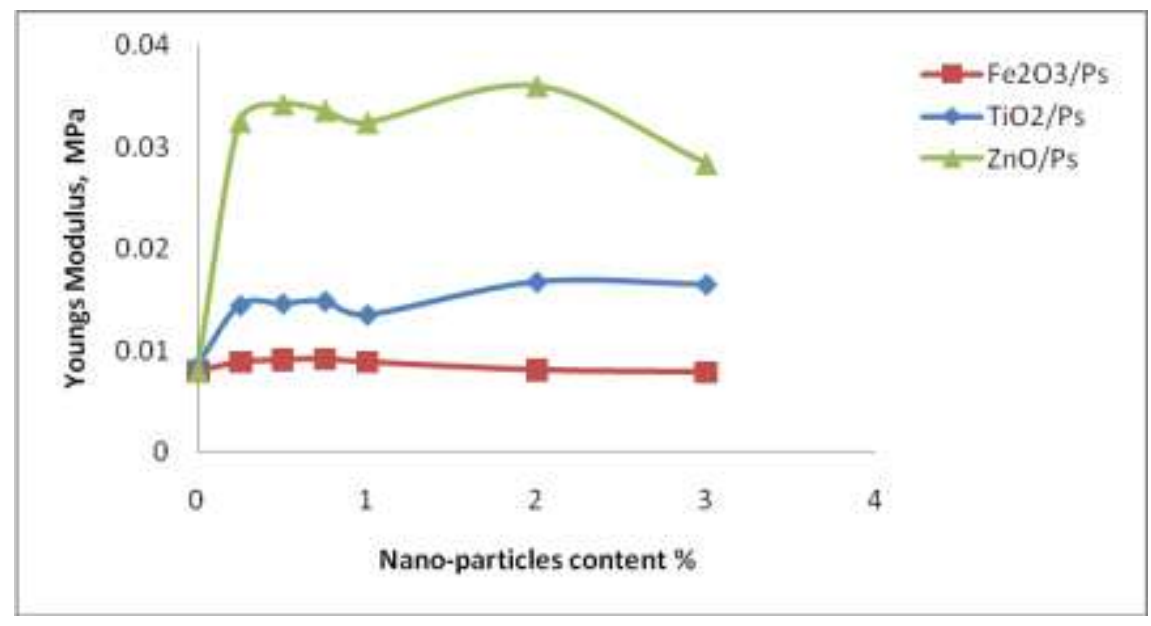

Fig.10. Effect of nano-particles content on the Young's modulus of PS/ nanocomposite 


\section{Conclusion}

Nano polystyrene sphere had been prepared through emulsion polymerization method using (SDS), also preparation of nano metal oxides depending on using (SDS) as capping agent, then nano polystyrene/nanocomposites prepared by sonication through solution casting method methodology at different concentrations of nano metals. The PS/nano metals composites were characterized by TEM, XRD and EDX. TEM images showed that PS have good mono dispersity with diameters of 60-80 $\mathrm{nm}$., different nano metals also have diameters in nano scale, as well as nano polystyrene/nano metals oxide composites showed a good dispersion on polystyrene film. Res ults from X-ray diffraction of nano metal oxides confirmed the presence of nano metal oxides in the samples. TGA results showed that adding metal oxides NPs in polystyrene film would increase thermal stability of product. Evaluating the effect of amount of metal oxide NPs on mechanical properties of polystyrene showed that the nanofiller increased the stability and elasticity module of polystyrene, and the results confirms that zinc oxide is the best filler which improved mechanical test due to the fact that the small diameter of these particles themselves and contribute a very high-interfacial surface area.

\section{References}

1. Tang, S., Chen, L., Vongehr, S. and Meng, X., Heterogeneous nucleation and growth of silver nanoparticles on unmodified poly styrene spheres by in situ reduction. Appl. Surf. Sci., 256, 2654-2660 (2010).

2. Lee, J.H., Mahmoud, M.A., Sitterle, V., Sitterle, J. and Meredith, J.C., Facile preparation of highly-scattering metal nanoparticle-coated polymer microbeads and their surface plasmon resonance. J. Am. Chem. Soc., 131, 5048-5049 (2009).

3. Wu, X.J. and Xu, D., Formation of yolk/SiO2 shell structures using surfactant mixtures as template. J. Am. Chem. Soc., 131, 2774-2775 (2009).

4. Wang, Y., Angelatos, A.S. and Caruso, F., Template synthesis of nanostructured materials via layer-by-layer assembly $\uparrow$. Chem. Mater., 20, 848-858 (2007).

5. Tovmachenko, O. G., Graf, C., van den Heuvel, D. J., van Blaaderen, A. and Gerritsen, H.C., Fluorescence enhancement by metal-core/silica - shell nanoparticles. Adv. Mater., 18, 91-95 (2006).

6. Kubo, S., Diaz, A., Tang, Y. and Mayer, T.S., et al., Tunability of the refractive index of gold nanoparticle dispersions. Nano Lett., 7, 3418-3423 (2007).

7. Godovsky, D.Y. in Biopolymers. PVA Hydrogels, Anionic Polymerisation Nanocomposites 163-205 (Springer, 2000).

8. Lerma-García, M., Ávila, M., Simó-Alfonso, E.F., Ríos, Á. and Zougagh, M., Synthesis of gold nanoparticles using phenolic acids and its application in cataly sis. $J$. Mater. Environ. Sci., 6, 1919-1926 (2014)

Egypt. J. Chem. 60, No. 2 (2017) 
9. Marinović-Cincović, M., Šaponjić, Z.V, Djoković, V., Milonjić, S. K. and Nedeljković, J. M., The influence of hematite nano-crystals on the thermal stability of polysty rene. Polym. Degrad. Stab., 91, 313-316 (2006).

10. Džunuzović, E.S., Džunuzović, J.V, Marinković, A.D., Marinović-Cincović, M.T., et al., Influence of surface modified TiO 2 nanoparticles by gallates on the properties of PMM A/TiO 2 nanocomposites. Eur. Polym. J., 48, 1385-1393 (2012).

11. Esthappan, S.K., Nair, A.B. and Joseph, R., Effect of cry stallite size of zinc oxide on the mechanical, thermal and flow properties of polypropylene/zinc oxide nanocomposites. Compos. Part B Eng., 69, 145-153 (2015).

12. Esthappan, S.K., Kuttappan, S.K. and Joseph, R., Effect of titanium dioxide on the thermal ageing of poly propylene. Polym. Degrad. Stab., 97, 615-620 (2012).

13. GÜLTEK, A., Seckin, T., ÖNAL, Y. and İÇDUYGU, M.G., Poly (methacrylic) acid and gamma-methacry loxy propyltrimethoxy silane/clay nanocomposites prepared by in-situ polymerization. Turkish J. Chem., 26, 925-938 (2002).

14. Hoffmann, B., Dietrich, C., Thomann, R., Friedrich, C. and Mülhaupt, R., Morphology and rheology of polystyrene nanocomposites based upon organoclay. Macromol. Rapid Commun., 21, 57-61 (2000).

15. Wizel, S., Margel, S. and Gedanken, A., The preparation of a polystyrene-iron composite by using ultrasound radiation. Polym. Int., 49, 445-448 (2000).

16. Kumar, R.V., Koltypin, Y., Palchik, O. and Gedanken, A., Preparation and characterization of nickel-polystyrene nanocomposite by ultrasound irradiation. $J$. Appl. Polym. Sci., 86, 160-165 (2002).

17. Navale, S.T., Khuspe, G.D., Chougule, M.A. and Patil, V.B., Synthesis and characterization of hybrid nanocomposites of polypyrrole filled with iron oxide nanop articles. J. Phys. Chem. Solids, 75, 236-243 (2014).

18. Kuljanin, J., MarinovićCincović, M., Zec, S., Čomor, M. I. and Nedeljković, J. M., Influence of Fe $2 \mathrm{O} 3$-filler on the thermal properties of polystyrene. J. Mater. Sci. Lett., 22, 235-237 (2003).

19. Bergeret, A. and Alberola, N., A study of the interphase in styrene-methacry lic acid copoly mer/glass bead composites. Polymer (Guildf)., 37, 2759-2765 (1996).

20. Š ajinović, D., Šaponjić, Z.V，Cvjetićanin, N., Marinović-Cincović, M. and Nedeljković, J. M., Synthesis and characterization of CdS quantum dots-poly sty rene composite. Chem. Phys. Lett., 329, 168-172 (2000).

21. Kuljanin, J., Vučković, M., Čomor, M. I., Bibić, N., et al. , Influence of CdS-filler on the thermal properties of poly sty rene. Eur. Polym. J., 38, 1659-1662 (2002).

22. Nair, P.S., Radhakrishnan, T., Revaprasadu, N., Van Sittert, C., et al., Characterization of polystyrene filled with $\mathrm{HgS}$ nanoparticles. Mater. Lett., 58, 361364 (2004). 
23. Xiao, M., Sun, L., Liu, J., Li, Y. and Gong, K., Synthesis and properties of polysty rene/graphite nanocomposites. Polymer (Guildf)., 43, 2245-2248 (2002).

24. Nakatani, Y. and Matsuoka, M., Effects of sulfate ion on gas sensitive properties of $\alpha-\mathrm{Fe} 2 \mathrm{O} 3$ ceramics. Jpn. J. Appl. Phys., 21, L758 (1982).

25. Liang, Y., Xia, X., Luo, . and Jia, Z., Synthesis and performances of Fe 2 O 3/PA-6 nanocomposite fiber. Mater. Lett., 61, 3269-3272 (2007).

26. Oh, J.K. and Park, J.M., Iron oxide-based superparamagnetic polymeric nanomaterials: design, preparation, and biomedical application. Prog. Polym. Sci., 36, 168-189 (2011).

27. Laachachi, A., Cochez, M., Ferriol, M., Lopez-Cuesta, J.M. and Leroy, E., Influence of TiO 2 and $\mathrm{Fe} 2 \mathrm{O} 3$ fillers on the thermal properties of poly (methyl methacry late) (PMMA). Mater. Lett., 59, 36-39 (2005).

28. Laachachi, A., Leroy, E., Cochez, M., Ferriol, M. and Cuesta, J.M.L., Use of oxide nanoparticles and organoclays to improve thermal stability and fire retardancy of poly (methyl methacry late). Polym. Degrad. Stab., 89, 344-352 (2005).

29. Ninjbadgar, T., Yamamoto, S. and Takano, M., Thermal properties of the $\gamma$-Fe 2 O 3/poly (methyl methacrylate) core/shell nanoparticles. Solid state Sci., 7, 33-36 (2005).

30. Hejazi, I., Hajalizadeh, B., S eyfi, J., Sadeghi, G.M.M., et al., Role of nanoparticles in phase separation and final morphology of superhydrophobic poly propylene/zinc oxide nanocomposite surfaces. Appl. Surf. Sci., 293, 116-123 (2014).

31. Ureña, Y.R.C., Bettini, S.H.P., Muñoz, P.R., Wittig, L., et al. , In situ sonochemical synthesis of $\mathrm{ZnO}$ particles embedded in a thermoplastic matrix for biomedical applications. Mater. Sci. Eng. C, 49, 58-65 (2015).

32. Nguyen, V.G., Thai, H., Mai, D.H., Tran, H.T. and Vu, M.T., Effect of titanium dioxide on the properties of polyethylene/TiO 2 nanocomposites. Compos. Part B Eng., 45, 1192-1198 (2013).

33. Wang, Z., Li, G., Peng, H., Zhang, Z. and Wang, X., Study on novel antibacterial high-impact poly sty rene/TiO2 nanocomposites. J. Mater. Sci., 40, 6433-6438 (2005).

34. Patra, N., Salerno, M., Cozzoli, P. D., Barone, A. C., et al. , Thermal and mechanical characterization of poly (methyl methacry late) nanocomposites filled with TiO 2 nanorods. Compos. Part B Eng., 43, 3114-3119 (2012).

35. Magalhaes, F. and Lago, R.M., Floating photocatalysts based on TiO 2 grafted on expanded polystyrene beads for the solar degradation of dyes. Sol. Energy, 83, 15211526 (2009).

36. Zan, L., Wang, S., Fa, W., Hu, Y., et al. , Solid-phase photocataly tic degradation of polystyrene with modified nano-TiO 2 catalyst. Polymer (Guildf)., 47, 8155-8162 (2006).

Egypt. J. Chem. 60, No. 2 (2017) 
37. Zan, L., Tian, L., Liu, Z. and Peng, Z., A new polystyrene-TiO 2 nanocomposite film and its photocatalytic degradation. Appl. Catal. A Gen., 264, 237-242 (2004).

38. Shang, J., Chai, M. and Zhu, Y., Solid-phase photocatalytic degradation of polystyrene plastic with TiO 2 as photocatalyst. J. Solid State Chem., 174, 104-110 (2003).

39. Jaleh, B., Madad, M.S., Tabrizi, M.F., Habibi, S., et al., UV-degradation effect on optical and surface properties of polystyrene-TiO2 nanocomposite film. J. Iran. Chem. Soc., 8, S161-S168 (2011).

40. Chu, H.H., Yeo, Y.S. and Chuang, K.S., Entry in emulsion polymerization using a mixture of sodium poly sty rene sulfonate and sodium dodecyl sulfate as the surfactant. Polymer (Guildf)., 48, 2298-2305 (2007).

41. Tauer, K., Can, H. K. and He, D., Influence of the peroxodisulfate counterion on the dodecyl sulfate adsorption onto polystyrene latex particles. Colloids Surfaces A Physicochem. Eng. Asp., 325, 7-16 (2008).

42. Boissier, C., Löfroth, J.E. and Nydén, M., Interactions between poly vinylpy rrolidone, sodium dodecylsulfate and nonylphenol ethoxylate in solution and on poly styrene particles. Colloids Surfaces A Physicochem. Eng. Asp., 301, 444 452 (2007).

43. Lin, Y., Ng, K.M., Chan, C.M., Sun, G. and Wu, J., High-impact polystyrene/halloysite nanocomposites prepared by emulsion polymerization using sodium dodecyl sulfate as surfactant. J. Colloid Interface Sci., 358, 423-429 (2011).

44. Abdel-Azim, S.M., Aboul-Gheit, A.K., Ahmed, S.M., El-Desouki, D.S. and AbdelMottaleb, M.S.A., Preparation and application of mesoporous nanotitania photocatalysts using different templates and $\mathrm{pH}$ media. Int. J. Photoenergy, 2014, (2014).

45. Solans, C., Izquierdo, P., Nolla, J., Azemar, N. and Garcia-Celma, M.J., Nanoemulsions. Curr. Opin. Colloid Interface Sci., 10, 102-110 (2005).

46. Kheirandish, M. and Borhani, S., Green prossesing of PS/nanoparticle fibers and studying morphology and properties. World Acad. Sci. Eng. Technol. Int. J. Chem. Mol. Nucl. Mater. Metall. Eng., 8, 192-195 (2014).

47. Kassaee, M.Z., Motamedi, E. and Majdi, M., Magnetic Fe 3 O 4-graphene oxide/polystyrene: fabrication and characterization of a promising nanocomposite. Chem. Eng. J., 172, 540-549 (2011).

48. Abulyazied, D.E., Mokhtar, S.M. and Motawie, A.M., Nanoindentation behavior and physical properties of polyvinyl chloride/styrene co-maleic anhydride blend reinforced by nano-bentonite. Journal of Applied Chemistry, 7, 2278-5736 (2014).

49. Han, K. and Yu, M., Study of the preparation and properties of UV - blocking fabrics of a PET/TiO2 nanocomposite prepared by in situ polycondensation. J. Appl. Polym. Sci., 100, 1588-1593 (2006). 
50. Jeon, I.Y. and Baek, J.B., Nanocomposites derived from polymers and inorganic nanop articles. Materials (Basel)., 3, 3654-3674 (2010).

51. Chae, D.W. and Kim, B.C., Characterization on polystyrene/zinc oxide nanocomposites prepared from solution mixing. Polym. Adv. Technol., 16, 846-850 (2005).

\section{الخو اص الفيزوكمياتية لمتر اكبات البولي ستيرين النانونية}

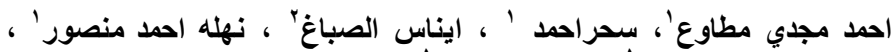

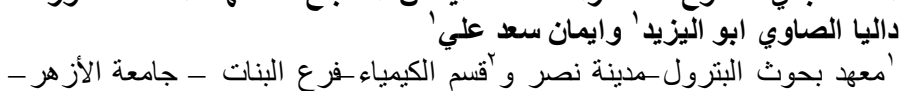

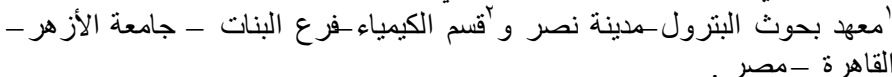

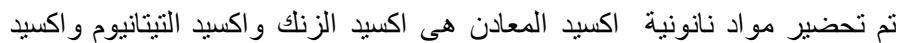

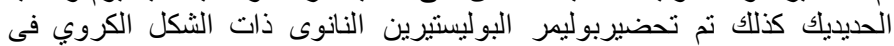

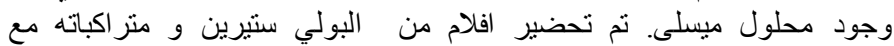

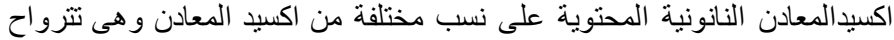

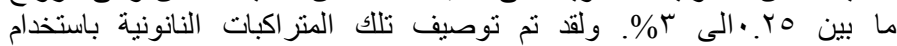

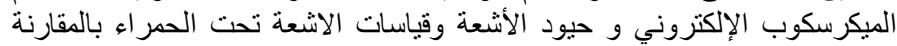

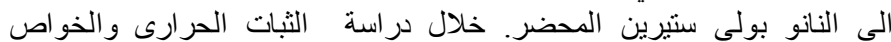

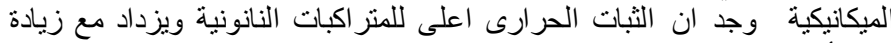

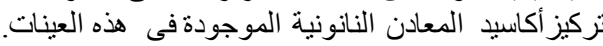

وتثبر النتائج إلى أن قوة الثد، استطالة عند الكسر ومعامل يونج للمتر اكبات

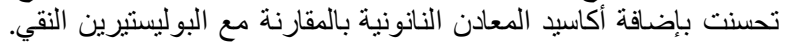

